\title{
Strong effect of climate on ectomycorrhizal fungal composition: evidence from range overlap between two mountains
}

\author{
Yumiko Miyamoto ${ }^{1}$, Atsushi Sakai ${ }^{2}$, Masahira Hattori ${ }^{3}$ and Kazuhide Nara ${ }^{1}$ \\ ${ }^{1}$ Department of Natural Environmental Studies, The University of Tokyo, Tokyo, Japan; ${ }^{2}$ Forestry and Forest \\ Products Research Institute, Kochi, Japan and ${ }^{3}$ Center for Omics and Bioinformatics, The University of \\ Tokyo, Tokyo, Japan
}

\begin{abstract}
Separating the effects of environmental factors and spatial distance on microbial composition is difficult when these factors covary. We examined the composition of ectomycorrhizal (EM) fungi along elevation gradients on geographically distant mountains to clarify the effect of climate at the regional scale. Soil cores were collected from various forest types along an elevation gradient in southwestern Japan. Fungal species were identified by the internal transcribed spacer regions of the rDNA using direct sequencing. The occurrence of fungal species in this study was compared with a previous study conducted on a mountain separated by $\sim 550 \mathrm{~km}$. In total, we recorded $454 \mathrm{EM}$ fungi from 330 of 350 soil cores. Forty-seven fungal species ( 20\% of the total excluding singletons) were shared between two mountains, mostly between similar forest types on both mountains. Variation partitioning in redundancy analysis revealed that climate explained the largest variance in EM fungal composition. The similarity of forest tree composition, which is usually determined by climatic conditions, was positively correlated with the similarity of the EM fungal composition. However, the lack of large host effects implied that communities of forest trees and EM fungi may be determined independently by climate. Our data provide important insights that host plants and mutualistic fungi may respond to climate change idiosyncratically, potentially altering carbon and nutrient cycles in relation to the plant-fungus associations.
\end{abstract}

The ISME Journal (2015) 9, 1870-1879; doi:10.1038/ismej.2015.8; published online 3 February 2015

\section{Introduction}

Ectomycorrhizal (EM) fungi establish obligate mutualistic relationships with many ecologically and economically important tree species, including Pinaceae, Fagaceae, Betulaceae and Dipterocarpaceae (Taylor and Alexander, 2005). EM fungi play a significant role in global nutrient and carbon cycles by enhancing the nutrient and water uptake by trees and absorbing carbon from their hosts (Smith and Read, 2008). Temperate and boreal forests, which cover $\sim 14 \%$ of the land surface (FAO, 2012), harbor hundreds of taxonomically and functionally diverse EM fungi (Read and PerezMoreno, 2003; Tedersoo et al., 2010; Koide et al., 2014). Recent environmental change may have altered fungal communities, which would subsequently affect the associated plant communities and ecosystem functioning (Parrent et al., 2006;

Correspondence: Y Miyamoto or K Nara, Department of Natural Environmental Studies, The University of Tokyo, 5-1-5 Kashiwanoha, Kashiwa 277-8563, Chiba, Japan.

E-mail: miyamoto_y@nenv.k.u-tokyo.ac.jp or nara@k.u-tokyo.ac.jp Received 13 August 2014; revised 13 December 2014; accepted 19 December 2014; published online 3 February 2015
Johnson et al., 2013; Dickie et al., 2014). Clarifying the drivers of the community structure of EM fungi is critical for predicting the effects of environmental change on forest ecosystems from local to global contexts (Lilleskov and Parrent, 2007).

Many studies have attempted to clarify the drivers of EM fungal composition at various scales and ecosystems. The host plant is regarded as one of the most important factors that influences EM fungal composition, especially at the stand scale, where hosts coexist in relatively narrow spatial and environmental ranges (Kennedy et al., 2003; Richard et al., 2005; Ishida et al., 2007; Tedersoo et al., 2008; Smith et al., 2009; Murata et al., 2013). However, isolating the host effect at larger spatial scales is difficult because the host composition changes with climatic conditions and geological history (Tedersoo et al., 2012). In addition, EM fungal communities may be affected by climate (Bahram et al., 2012) and soil (Cox et al., 2010; Jarvis et al., 2013; Roy et al., 2013). Moreover, EM fungal communities often exhibit spatial structures (Lilleskov et al., 2004; Bahram et al., 2013a; Miyamoto et al., 2014), which may be driven by autocorrelations in environmental factors 
(Toljander et al., 2006; Tedersoo et al., 2012) or independently by fungal internal factors (e.g., dispersal; Peay et al., 2007). Thus, at larger regional and global scales, whether EM fungal communities are differentiated by hosts, environmental factors or geographical distance is less clear. Distinguishing the effects of these factors is critical to determine if fungal distributions are primarily constrained by contemporary environmental variations or by past dispersal events (Martiny et al., 2006). Systematic sampling strategies are needed to address the relative importance of these factors at larger spatial scales.

The community structures of EM fungi are often examined by standard ordination and distance methods (Bahram et al., 2012; Põlme et al., 2013). However, unlike plant and animal community studies, the distribution and overlap of individual species of soil fungi between sites has rarely been reported, mainly because soil fungi are difficult to detect and quantify accurately in the field without applying molecular analyses. In addition, many EM fungi are observed rarely and sporadically because of the inherently limited sampling efforts relative to the entire soil volume (Taylor, 2002). Our previous study (Miyamoto et al., 2014) demonstrated that intensive sampling (many samples from each community) is effective for recording a relatively large number of fungal taxa in a community and for identifying species overlaps among study sites. Consistent sampling across study sites also helps to remove the variations imposed by methodological discrepancies found in many meta-analyses (Nakagawa and Santos, 2012; Tedersoo et al., 2014). A detailed examination of species overlaps among communities improves the chances of detecting distribution patterns, community structures and the underlying mechanisms of organisms (Leibold and Mikkelson, 2002; Presley et al., 2010; Thébault, 2013).

Here, we established study sites along an elevation gradient from a warm temperate to boreal climate on a mountain and examined the EM fungal community at each site. The data collected were combined with the data from our previous study conducted on Mt. Fuji, which is located $\sim 550 \mathrm{~km}$ away (Miyamoto et al., 2014). Each elevation gradient encompassed a wide range in climate within a short geographical distance, and different types of forest were present at similar altitudes on both mountains. Specifically, we tested the following hypotheses: (1) fungal species occurring on the two mountains are distributed in the same environmental conditions; (2) compositions of EM fungi and trees are positively related; and (3) host phylogeny relatedness drives EM fungal composition. We then discuss the relative importance of environmental factors, host phylogeny, geographical distance or combination of these factors on EM fungal composition.

\section{Materials and methods}

Study sites and sampling

Field sampling was conducted on the south slope of Mt. Ishizuchi, western Japan, in 2012. This area has a temperate climate characterized by warm, wet summers and cool, moderately dry winters. We established three study sites in closed-canopy natural forests along an elevation gradient on the mountain (Table 1). Site I1 $(850 \mathrm{~m})$ was an evergreen broadleaf and conifer mixed forest dominated by Tsuga sieboldii (37\% of the relative basal area), Abies firma $(22 \%)$ and Quercus salicina (21\%). Site I2 (1450m) was a deciduous and conifer mixed forest dominated by Fagus crenata (49\%) and Abies homolepis (16\%). Site I3 $(1850 \mathrm{~m})$ was a subalpine conifer forest that was exclusively dominated by Abies veitchii (96\%). The composition of tree species along the elevation represented a typical vegetation change in the southwest part of Japan. The highest sampling site $(1850 \mathrm{~m})$ was located just below the treeline.

Field sampling was conducted according to Miyamoto et al., 2014. Briefly, 50 rectangular soil

Table 1 Description of study sites on Mt. Ishizuchi

\begin{tabular}{|c|c|c|c|}
\hline Site & I1 & I2 & I3 \\
\hline Elevation (m) & 850 & 1450 & 1850 \\
\hline \multirow[t]{2}{*}{ Coordinates } & $\mathrm{N} 33^{\circ} 44^{\prime}$ & $\mathrm{N} 33^{\circ} 44^{\prime}$ & $\mathrm{N} 33^{\circ} 46^{\prime}$ \\
\hline & $\mathrm{E} 133^{\circ} 07^{\prime}$ & $\mathrm{E} 133^{\circ} 09^{\prime}$ & $\mathrm{E} 133^{\circ} 07^{\prime}$ \\
\hline Temperature $\left({ }^{\circ} \mathrm{C}\right)^{\mathrm{a}}$ & 9.4 & 6.2 & 4.6 \\
\hline Precipitation $(\mathrm{mm})^{\mathrm{a}}$ & 2823 & 3137 & 2806 \\
\hline Tree density (stems per ha) & 2363 & 2450 & 963 \\
\hline Tree basal area $\left(\mathrm{m}^{2}\right.$ per ha) & 46.9 & 39.1 & 33.2 \\
\hline Number of tree species & 34 & 25 & 10 \\
\hline Number of host tree species & 4 & 4 & 3 \\
\hline $\mathrm{pH}\left(\mathrm{H}_{2} \mathrm{O}\right)^{\mathrm{b}}$ & $3.5-5.5(4.1)$ & $3.4-4.7(3.8)$ & $3.4-4.8(3.8)$ \\
\hline $\mathrm{C} / \mathrm{N}^{\mathrm{b}}$ & $11.9-36.9(18.3)$ & $9.0-20.8(15.6)$ & $6.8-21.2(17.3)$ \\
\hline Litter $(\mathrm{cm})^{\mathrm{b}}$ & $0-5.0(2.4)$ & $0.5-5.0(1.9)$ & $0.5-4.0(1.7)$ \\
\hline
\end{tabular}

Abbreviation: $\mathrm{C} / \mathrm{N}$, carbon/nitrogen.

${ }^{a}$ Site-specific mean annual temperature and mean annual precipitation obtained from the interpolated mesh data $\left(1 \times 1 \mathrm{~km}^{2} ; 30\right.$-year averages from 1981-2010) provided by The Japan Meteorological Agency, 2014.

${ }^{b}$ Values are minimum-maximum with the mean in parentheses. 
cores $(5 \times 5 \mathrm{~cm}$ to $10 \mathrm{~cm}$ depth) were collected from a 1-ha area at each site. A minimum distance of 5-10 m was maintained between soil-sampling locations to ensure sample independence (Lilleskov et al., 2004; Pickles et al., 2012). A vegetation survey was conducted at every other soil-sampling location. Tree species and diameter at breast height $(1.3 \mathrm{~m})$ were recorded for all living trees ( $>1.3 \mathrm{~m}$ tall) within a $5-\mathrm{m}$ radius of the sampling point. Litter depth and geographical coordinates (Garmin 62S; Garmin International, Olathe, KS, USA) were recorded at each sampling point.

\section{Molecular analyses}

We followed Miyamoto et al., 2014 for the molecular analyses. Briefly, all roots were collected from each soil sample, and EM root tips were classified by their morphological characteristics. Three healthy EM root tips were sampled from each morphotype of each core for molecular analyses. The cetyltrimethyl ammonium bromide method was used to extract fungal DNA from the root tips. A polymerase chain reaction (PCR) was performed to amplify the internal transcribed spacer (ITS) regions (ITS1, 5.8S and ITS2) of the rDNA using the forward primer ITS1F and reverse primers (i.e., ITS4, LR21 and LR22). Replicates of each morphotype were compared based on restriction fragment length polymorphism (RFLP) patterns using Hinfl and AluI restriction enzymes, and unique RFLP types in a morphotype were subjected to direct sequencing (3730xl DNA analyzer; Applied Biosystems, Foster City, CA, USA). PCR products were purified and sequenced using primer ITS1. Primer ITS4 was used for poorly sequenced samples. All sequences were manually inspected using chromatograms. High-quality sequences with $>350$ bp were trimmed, aligned and clustered into molecular operational taxonomic units (hereafter referred to as 'species') at $\geqslant 97 \%$ similarity using the alignment software ATGC ver. 7 (Genetyx Corp., Tokyo, Japan). The sequences were compared with those deposited in the International Nucleotide Sequence Database (INSD). Sequences that showed a high degree of similarity with saprophytic and pathogenic fungi or nonfungal taxa were removed from the analyses. Cenococcum geophilum (hereafter referred to as 'Cg') was identified primarily based on its unique morphology as in previous studies (Twieg et al., 2007; Murata et al., 2013), while a few Cg operational taxonomic units were detected through molecular analyses. Host trees associated with EM fungi were identified to the genus level by amplifying the plastid trnL region of plant DNA using the primer pairs trnC-trnD and trnE-trnF (Taberlet et al., 1991). RFLP patterns were then compared with those obtained from the leaves of host species recorded in the field. Direct sequencing was additionally applied to those samples with unclear RFLP patterns.
Soil data collection

Soil pH, total carbon (C), and total nitrogen (N) of each sample were measured according to Miyamoto et al., 2014. Soil $\mathrm{pH}$ was measured from a 5-g air-dried soil sample in a 1:5 ratio with Milli-Q water (Millipore, Billerica, MA, USA) using a HM25G glass electrode (DKK-TOA Corp., Tokyo, Japan). Total $\mathrm{C}$ and $\mathrm{N}$ were measured by dynamic flash combustion with a CN Analyzer (Flash EA 1112; AMCO Inc., Tokyo, Japan).

\section{Statistical analyses}

We combined the data from this study with those of a previous study conducted on Mt. Fuji (Miyamoto et al., 2014) and analyzed the combined data to reveal community structures at a regional scale. Fungal species recorded on Mt. Ishizuchi and Mt. Fuji were matched based on a $\geqslant 97 \%$ sequence similarity. Sites on Mt. Fuji were reassigned as F1 (site 1, elevation $1100 \mathrm{~m}$ ), F2 (site 2, $1550 \mathrm{~m}$ ), F3 (site 3, $1900 \mathrm{~m}$ ) and F4 (site 4, $2250 \mathrm{~m}$ ). The forest types in the seven sites were defined based on the composition of all tree species (using a single-linkage agglomerative clustering of tree compositions; Supplementary Figure S1). Four forest types were identified: subalpine conifer (Abies-Tsuga-dominated; F3, F4, I3), cool temperate mixed (Abies-Fagus-dominated; F2, I2), warm temperate deciduous (Quercus-dominated; F1) and warm temperate mixed (Abies-Quercus-dominated; I1). The estimated richness (Chao 2 nonparametric estimators) was computed using EstimateS (version 8.20; Colwell et al., 2012) with 5000 randomizations without replacement. $\mathrm{R}$ version 3.0.3 ( $\mathrm{R}$ Development Core Team, 2013) was used for statistical analyses, with the significance level set to $P=0.05$ (unless otherwise noted). Singleton species that were recorded in one core across the entire data set were removed from community analyses.

The degree of species overlaps between EM fungal communities was calculated as the number of shared species divided by the total number of species recorded at each pair of sites. Fisher's exact tests were conducted to test whether the fungal species found on both mountains ('mountain-shared species') that were recorded at a particular site occurred randomly at sites on another mountain (e.g., the null hypothesis was that the mountainshared species that were recorded at F1 on Mt. Fuji were randomly distributed at I1, I2 and I3 on Mt. Ishizuchi). The mountain-shared species were tested to determine whether the frequency of the species was biased toward particular forest types using Fisher's exact test. The Benjamini and Hochberg false discovery rate correction (Verhoeven et al., 2005) was performed to adjust type I error for multiple comparisons using the fmsb package of $\mathrm{R}$.

The occurrence of fungal species per site was treated as a sample unit $(n=7)$ for community analyses. The relationship between EM fungal and tree species composition similarities was tested 
using the Mantel test with Bray-Curtis distance matrices. Spatial autocorrelation among the fungal composition was tested using the Mantel test with fungal composition against the Euclidean distance of a geographical matrix. Significance was tested with 9999 permutations. Separation of EM fungal composition by location (Mt. Fuji vs Mt. Ishizuchi) and forest type was tested using Adonis (permutation-based multivariate analysis of variance) in the vegan package of $\mathrm{R}$. Adonis partitions a distance matrix among categorical or continuous variables, and computes the strength and significance of the explanatory variables (Anderson, 2001). The significance was tested with 999 permutations. Community dissimilarities were visualized in twodimensional space using nonmetric multidimensional scaling (NMDS) with 999 permutations. Bray-Curtis distances were calculated prior to Adonis and NMDS visualization. The effect of individual environmental variables on NMDS ordination was examined using environmental fitting tests in the envfit function in vegan, and the significance of vectors was tested with 999 permutations. The variables included were climate (mean annual temperature and mean annual precipitation), soil (C/N, pH and litter depth) and geographical distance. Soil variables were log transformed prior to analyses. Geographical distance (latitude and longitude) was transformed to the principal coordinates of neighbor matrices (PCNM) vectors that represented the geographical distances at various spatial scales (Borcard et al., 2004; Dray et al., 2006). PCNM vectors were calculated from the pairwise Euclidean distance of geographical coordinates between study sites.

Furthermore, the EM fungal community per host per site was treated as a sample unit $(n=19)$ in analyses to evaluate the effect of host identity. Hosts represented by $\leqslant 5$ cores were excluded from the analysis. The relative effects of climate, soil, host identity and geographical distance were analyzed using variation partitioning in redundancy analyses (the varpart function in vegan). Forward selection by redundancy analysis was used prior to variation partitioning to identify significant variables associated with EM fungal compositions based on 999 permutations (Borcard et al., 2011). Only significant variables were used to compute the total variance of the EM fungal composition explained by these variables.

Host identity was measured as the phylogenetic distance among the seven host genera, computed according to Tedersoo et al., 2013. Plastid matK and trnL gene sequences were downloaded from INSD or generated during our molecular host identification (Supplementary Table S1). These regions sufficiently distinguished host genus, whereas they were identical at the species level. Sequences of each region were aligned using MAFFT v.7.147 (http:// mafft.cbrc.jp/alignment/software/) with the iterative refinement method (L-INS-i algorithm; Katoh and
Toh, 2008). A phylogenetic tree was constructed using trnL-matK by applying maximum likelihood algorithms with a general time reversible model and 500 bootstrap replicates using MEGA ver. 6.0 (Tamura et al., 2013). Pairwise patristic distances (pairwise sum of the branch length connecting two terminal taxa) were then calculated using the ape package of $R$. The pairwise patristic distance matrix was converted to phylogenetic eigenvectors using principal coordinate analysis. Principal coordinate analysis vectors are orthogonal and represent phylogenetic distances of host trees. Significant eigenvectors were forward selected prior to analyses.

\section{Results}

General descriptions of EM fungi on Mt. Ishizuchi In total, 1469 root tips were collected for molecular analyses; 1371 tips (93\%) were successfully amplified and 1206 tips were identified to species by RFLP and sequencing analyses. Thirteen sequences did not belong to EM fungal taxa. In total, 465 of 514 cumulative morphotypes (90\%) were successfully identified to species. We recorded 200 species on Mt. Ishizuchi, including 110 singletons (55.0\%) and 39 doubletons (19.5\%; Supplementary Table S2). The mean length of our sequences was $584 \mathrm{bp}$ and $88 \%$ of the sequences (134 of 152 newly detected species) were longer than $500 \mathrm{bp}$. The most frequently observed lineages included /russula-lactarius (49 species) and /tomentella-thelephora (38 species). The most frequently observed species was $\mathrm{Cg}$ (76 of 150 soil cores; 50.7\%), followed by Clavulina castaneipes (25 cores; 16.7\%) and Russula granulata (19 cores; 12.7\%). Seven species occurred at all sites. The observed species richness was 93 at site I1, 98 at site I2 and 55 at site I3. The rarefaction curves of Chao 2 estimated richness, reached an asymptote at site I1 but did not become asymptotic at sites I2 and I3 (Supplementary Figure S2). The Chao 2 estimated richness on Mt. Ishizuchi was $355 \pm 40.6$. Exceptionally abundant Cg, which likely contained some cryptic species (Douhan and Rizzo, 2005), was removed from further analyses.

\section{Species overlaps among communities}

In total, 453 EM fungal species (excluding $\mathrm{Cg}$ ) were recorded from the two mountains, including 225 singletons (49.7\%) and 89 doubletons (19.6\%). Pearson's linear correlation showed that EM fungal richness (Chao 2) was positively correlated with belowground host genus richness $(r=0.83$; $\left.t_{5}=3.34 ; P=0.021\right)$. Singleton species that were found in one core across the entire data set were removed to improve community analyses, leaving 228 species for further analyses.

A total of 47 species were shared between the mountains (Figure 1 and Table 2). Sites F2 and I2 (cool temperate mixed forest pairs) shared 20 
species $(18.4 \%$ of the total number of species recorded at these sites). Sites F3 and I3 (Abiesdominated subalpine conifer forest pairs) shared 14 species $(14.1 \%)$. These shared fungi occurred across multiple host genera (Supplementary Figure S3). Fisher's exact test with false discovery rate correction showed that the mountain-shared species recorded in the subalpine conifer forests on Mt. Fuji (sites F3 and F4) occurred at significantly higher frequencies in the subalpine conifer forest (site I3) than in the other forest types (site I1 or I2) on Mt. Ishizuchi $(P<0.043)$. Similarly, the mountain-shared species recorded at site I3 on Mt. Ishizuchi occurred at a significantly higher frequency at site F3 on Mt. Fuji $(P=0.019)$. The mountain-shared species in the mixed forest on Mt. Ishizuchi (site I2) also occurred at higher frequency in the mixed forest on Mt. Fuji (site F2) at $P=0.085$. Approximately, $66 \%$ (31 of 47) of mountain-shared species occurred in particular forest types, and Fisher's exact test showed significantly biased frequency of occurrence in some fungal species (Table 2).

\section{Composition and underlying mechanisms}

A Mantel test showed that the similarities in EM fungal composition were significantly correlated with those of forest tree composition $\left(r_{\mathrm{M}}=0.47\right.$, $P=0.042)$, but not with geographical distance $(P=0.146)$ at the regional scale. A partial Mantel test revealed that geographical distance was significant when the effect of tree composition was

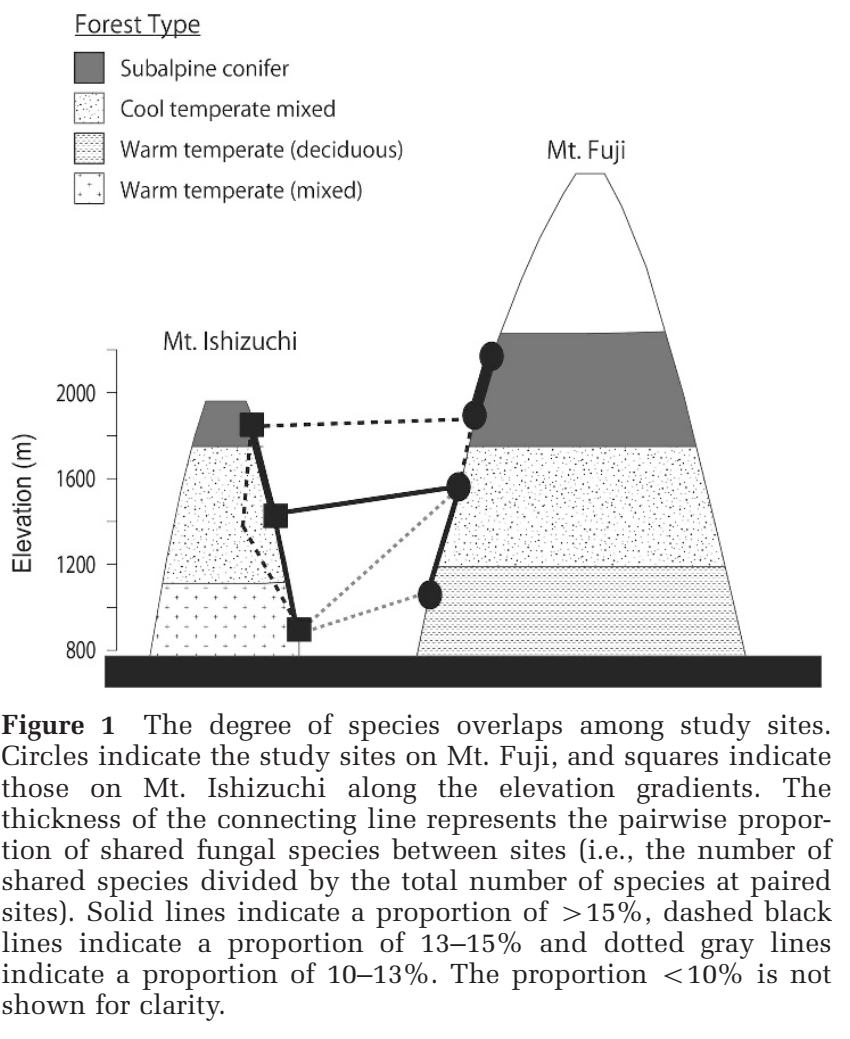

excluded $\left(r_{\mathrm{M}}=0.45, P=0.033\right)$. Tree composition remained significant when the distance effect was excluded $\left(r_{\mathrm{M}}=0.55, P=0.024\right)$. An Adonis test showed that the larger variance was explained by forest type than location (Figure 2a and Table 3).

Furthermore, the EM fungal composition on Abies, which occurred at six of the seven studied sites, was analyzed separately to remove host effects. The results were similar to those of the entire community (Supplementary Figure S4). An Adonis test showed that forest type explained the larger variance in fungal composition $\left(F_{2,2}=1.75\right.$, $\left.R^{2}=0.47 ; \quad P=0.02\right) \quad$ than location $\left(F_{1,2}=1.96\right.$, $\left.R^{2}=0.26 ; P=0.03\right)$.

EM fungal communities on individual hosts per site were separated by forest type and environmental factors (Figure 2b). Variation partitioning showed that climate (temperature and precipitation) alone explained the largest variance $\left(R_{\text {adj }}^{2}=0.13\right)$ in the EM fungal composition, followed by soil $(\mathrm{C} / \mathrm{N}$ and $\mathrm{pH} ; \quad R^{2}$ adj $\left.=0.05\right)$ and geographical distance $\left(R_{\text {adj }}^{2}=0.04\right.$; Figure 3$)$. No significant effect of host identity alone was detected in variation partitioning. Temperature, precipitation, $\mathrm{C} / \mathrm{N}$ and host identity were significantly correlated with NMDS vectors based on the environmental fitting test (Table 4).

\section{Discussion}

Differentiating the effects of host, environment and geographical distance on EM fungal communities is difficult when these factors covary at large spatial scales (Toljander et al., 2006; Tedersoo et al., 2012; Miyamoto et al., 2014). We applied relatively intensive and consistent sampling methods and recorded 454 EM fungal species from 330 of 350 soil samples along two elevation gradients. This is among the highest richness reported from one region, which enabled us to show the degree of species overlaps between similar habitats on geographically distant mountains. We demonstrated that $\sim 20 \%$ of the EM fungal species occurred on the two mountains and they tended to inhabit similar forest types (Figure 1 and Table 2). The species overlaps were particularly notable between the cool temperate mixed forests on both mountains, where the highest proportion (18.4\%) of EM fungi overlapped despite the geographical distance of $\sim 550 \mathrm{~km}$. In contrast, only one and five EM fungal species were shared between nonadjacent sites within Mt. Fuji (F2 and F4) or Mt. Ishizuchi (I1 and I3), respectively, despite the close geographical distances of $<10 \mathrm{~km}$, indicating a weak effect of geographical distance per se (Miyamoto et al., 2014). These results suggest that some EM fungi are widely distributed across the region and their presence is constrained by contemporary environmental factors. To support this, many mountain-shared species (31 of 47 species or $66.0 \%$ ) displayed niche preferences to particular forest types (Table 2). Those EM 
Table 2 List of mountain-shared species

\begin{tabular}{|c|c|c|c|c|c|c|c|c|c|}
\hline \multirow[t]{2}{*}{ Forest type } & \multirow[t]{2}{*}{ Species } & \multicolumn{4}{|c|}{ Fuji } & \multicolumn{3}{|c|}{ Ishizuchi } & \multirow[t]{2}{*}{$\mathrm{P}$-value } \\
\hline & & F1 & F2 & F3 & $F 4$ & I1 & I2 & I3 & \\
\hline \multirow[t]{8}{*}{ Subalpine conifer } & Clavulinaceae sp.5 & & & $\bullet$ & 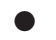 & & & $\mathbf{\square}$ & * \\
\hline & Clavulina castaneipes & & & 0 & 0 & & $\square$ & $\overline{\mathbf{a}}$ & * \\
\hline & Cortinarius scaurus sp.1 & & & $\bullet$ & $\bullet$ & & & & * \\
\hline & Sebacina sp. 3 & & & - & - & & & $\mathbf{\square}$ & \\
\hline & Lactarius imperceptus & & & $\bullet$ & & & & $\overline{\mathbf{a}}$ & * \\
\hline & Amanita sp.1 & & & 0 & & & & $\overline{\mathbf{\square}}$ & \\
\hline & Piloderma sp.3 & & & 0 & & & & $\overline{\mathbf{\square}}$ & \\
\hline & Sebacina sp.29 & & & - & & & & $\mathbf{\square}$ & \\
\hline \multirow[t]{6}{*}{ Cool temperate mixed } & Genea hispidula & & 0 & & & & a & & \\
\hline & Russula sp.2 & & 0 & & & & $\mathbf{\square}$ & & \\
\hline & Russula sp.12 & & 0 & & & & $\bar{\square}$ & & \\
\hline & Tomentella sp.6 & & 0 & & & & 口 & & \\
\hline & Tomentella sp.12 & & 0 & & & & $\bar{\square}$ & & \\
\hline & Tomentella sp.50 & & 0 & & & & $\bar{\square}$ & & \\
\hline \multirow{13}{*}{$\begin{array}{l}\text { Cool temperate mixed and warm temperate } \\
\text { (deciduous and mixed) }\end{array}$} & Cortinarius sp.17 & & 0 & & & $\square$ & $\square$ & & \\
\hline & Tuber sp.2 & & 0 & & & $\square$ & $\mathbf{\square}$ & & \\
\hline & Inocybe sp.15 & & 0 & & & $\square$ & & & \\
\hline & Tomentella sp.11 & & 0 & & & $\square$ & & & \\
\hline & Tomentella stuposa sp.1 & & 0 & & & $\square$ & & & \\
\hline & Entoloma sp.1 & $\bigcirc$ & 0 & & & $\square$ & $\mathbf{\square}$ & & * \\
\hline & Laccaria sp.1 & 0 & 0 & & & $\square$ & $\mathbf{a}$ & & * \\
\hline & Sebacina sp.4 & $\bigcirc$ & 0 & & & $\square$ & $\bar{\square}$ & & * \\
\hline & Xerocomus sp.2 & 0 & 0 & & & $\square$ & 口 & $\mathbf{\square}$ & * \\
\hline & Cortinarius anomalus & $\bigcirc$ & & & & $\square$ & $\bar{\square}$ & & * \\
\hline & Cortinarius sp.14 & 0 & & & & & $\bar{a}$ & & \\
\hline & Cortinarius umbrinolens & $\bigcirc$ & & & & & $\mathbf{\square}$ & & \\
\hline & Lactarius quietus & $\bigcirc$ & & & & & $\bar{\square}$ & & \\
\hline \multirow[t]{4}{*}{ Warm temperate (deciduous and mixed) } & Entoloma sp.3 & 0 & & & & $\square$ & & & * \\
\hline & Tomentella sp.41 & 0 & & & & $\square$ & & & \\
\hline & Tomentella sp.48 & $\bigcirc$ & & & & $\square$ & & & \\
\hline & Xerocomus sp.3 & $\bigcirc$ & & & & $\square$ & & & \\
\hline \multirow[t]{16}{*}{ Various forests } & Clavulinaceae sp.1 & & & 0 & $\bullet$ & & 口 & & \\
\hline & Inocybe sp.11 & & & - & - & & a & $\mathbf{\square}$ & \\
\hline & Laccaria cf. laccata sp. 2 & & 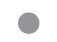 & & & & $\bar{\square}$ & $\mathbf{\square}$ & \\
\hline & Russula peckii & & 0 & - & & & & $\mathbf{\square}$ & \\
\hline & Russula turci & & & & ○ & $\square$ & & $\mathbf{\square}$ & \\
\hline & Sebacina sp.1 & & 0 & - & - & & 口 & $\mathbf{\square}$ & \\
\hline & Sebacina sp.2 & & & - & - & $\square$ & & $\mathbf{\square}$ & \\
\hline & Sebacina sp.20 & & 0 & & & & $\square$ & $\mathbf{\square}$ & \\
\hline & Thelephoraceae sp.2 & & 0 & & & $\square$ & $\bar{\square}$ & $\mathbf{\square}$ & \\
\hline & Tomentella sp.5 & & 0 & 0 & & $\square$ & $\bar{\square}$ & & \\
\hline & Tomentella sp.7 & & 0 & - & & $\square$ & $\bar{\square}$ & & \\
\hline & Tomentella sp.8 & & 0 & - & & $\square$ & a & $\mathbf{\square}$ & \\
\hline & Tomentella sp.18 & & 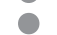 & - & & & 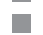 & & \\
\hline & Tomentella sp.21 & & & - & - & $\square$ & & & \\
\hline & Tomentella sp.31 & & & - & & $\square$ & & [ & \\
\hline & Tomentella sublilacina & 0 & & & & & a & $\mathbf{\square}$ & \\
\hline
\end{tabular}

Symbols indicate the presence of a species. Circles represent sites on Mt. Fuji and squares represent sites on Mt. Ishizuchi. Forest types are subalpine conifer forest (black), cool temperate mixed forest (gray) and warm temperate mixed and deciduous forest (white). Asterisks indicate species whose frequency is significantly biased by forest type based on Fisher's exact tests after false discovery rate (FDR) correction.

fungal species restricted to particular habitats are likely more sensitive to environmental change than habitat generalists (Carignan and Villard, 2002), such as Tomentella sublilacina and Laccaria laccata, which were recorded across wide environmental ranges.

Variation partitioning further indicated that environmental factors (i.e., climate and soil) had a stronger effect on the EM fungal composition than geographical distance or host identity (Figure 3). Previous studies have reported the importance of climate (Bahram et al., 2012; Tedersoo et al., 2012) and soils (Cox et al., 2010; Jarvis et al., 2013) on EM fungal composition at regional to global scales. However, the potential effects of climate remain unclear because climate covaries with spatial distance in these studies. Alternatively, Põlme et al., 2013 and Roy et al., 2013 examined a single host genus (i.e., Alnus) and identified significant spatial structures in the EM fungal compositions, but environmental factors had a stronger influence on the community structures. Alnus is associated with 


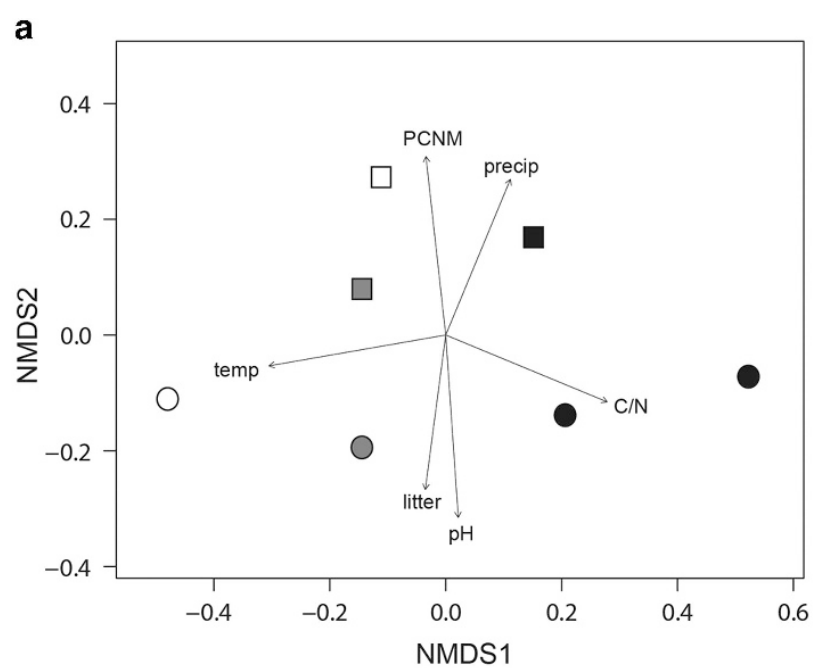

b
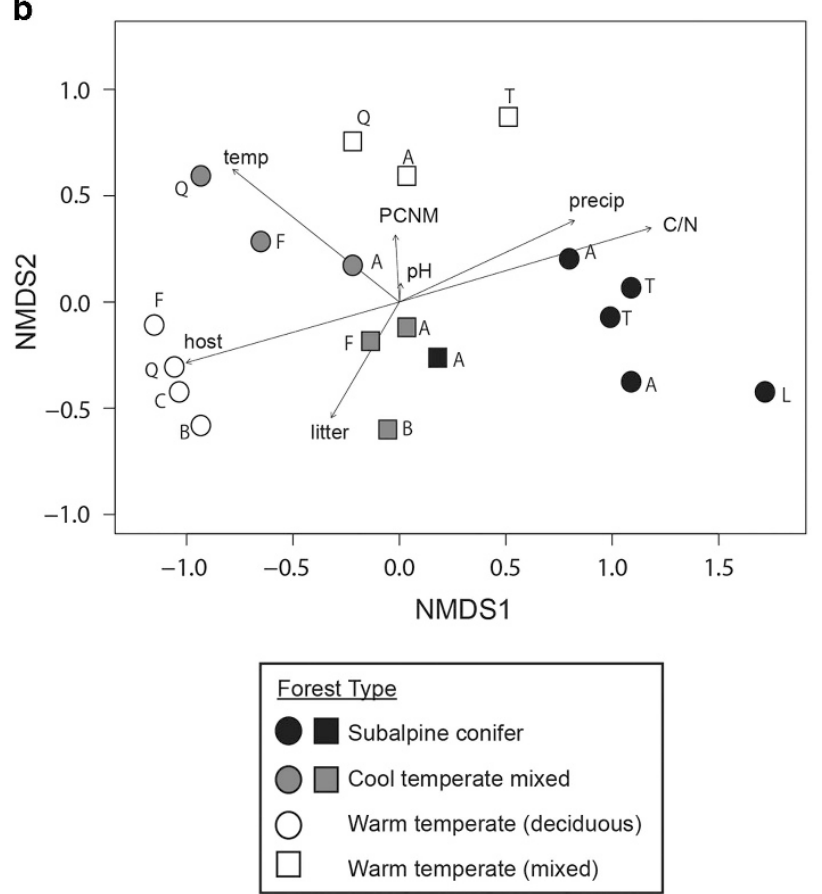

Figure 2 Nonmetric multidimensional scaling (NMDS) graphs of the ectomycorrhizal fungal communities. Environmental variables are fitted to the NMDS ordination. The abbreviations are temp (temperature), precip (precipitation), host (host phylogenetic eigenvector) and PCNM (spatial principal coordinates of neighbor matrices eigenvector). The significance of the vectors is shown in Table 4. Circles and squares indicate sites on Mt. Fuji and Mt. Ishizuchi, respectively. (a) Seven sites (stress $=0.08$ ) and (b) 19 host communities (stress $=0.10$ ). Host genera are Fagus $(\mathrm{F})$, Quercus (Q), Betula (B), Carpinus (C), Abies (A), Tsuga (T) and Larix (L). Three-dimensional NMDS graphs were included in Supplementary Figure S5.

N-fixing bacteria and usually form unique EM fungal communities with low diversity (Kennedy and Hill, 2010). Our results indicated that a stronger effect of environmental factors than geographical distance could be applicable to the more speciesrich EM fungal communities that are associated with many typical EM host genera. This was further
Table 3 Effect of forest type and location in separating the ectomycorrhizal fungal composition (Bray-Curtis distance) as revealed by the Adonis test

\begin{tabular}{lcccccc}
\hline & $D F$ & $S S$ & $M S$ & F-statistic & $\mathrm{R}^{2}$ & P-value \\
\hline Forest type & 3 & 1.41 & 0.47 & 2.22 & 0.59 & 0.003 \\
Location & 1 & 0.56 & 0.56 & 2.66 & 0.24 & 0.006 \\
Residuals & 2 & 0.42 & 0.42 & & & \\
Total & 6 & 2.4 & 2.39 & & & \\
\hline
\end{tabular}

Abbreviations: DF, degree of freedom; MS, mean square; SS, sum of squares.

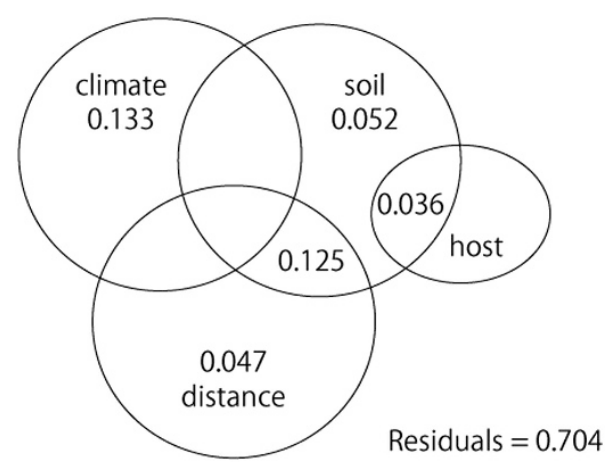

Figure 3 Individual and interaction effects of putative factors explaining 19 ectomycorrhizal fungal community compositions as revealed by variation partitioning in redundancy analyses. Values are adjusted $R^{2}(<0.01$ are not shown). Factors include climate (mean annual temperature and mean annual precipitation), soil ( $\mathrm{C} / \mathrm{N}$ and $\mathrm{pH}$ ), distance (spatial principal coordinates of neighbor matrices eigenvector) and host (host phylogenetic eigenvector).

Table 4 Effects of environmental variables on fungal composition fitted to the nonmetric multidimensional scaling ordination

\begin{tabular}{lcc}
\hline Variables & $\mathrm{R}^{2}$ & P-value \\
\hline (a) 7 Sites & & \\
Annual temperature & 0.795 & $\mathbf{0 . 0 4 3}$ \\
Annual precipitation & 0.703 & 0.057 \\
PCNM vector & 0.799 & 0.067 \\
pH & 0.828 & 0.055 \\
C/N & 0.754 & 0.069 \\
Litter & 0.601 & 0.144 \\
(b) 19 Host communities & & \\
Annual temperature & 0.579 & $\mathbf{0 . 0 0 3}$ \\
Annual precipitation & 0.476 & $\mathbf{0 . 0 0 6}$ \\
PCNM vector & 0.058 & 0.640 \\
pH & 0.005 & 0.973 \\
C/N & 0.903 & $\mathbf{0 . 0 0 1}$ \\
Litter & 0.141 & 0.318 \\
Host & 0.628 & $\mathbf{0 . 0 0 2}$ \\
\hline
\end{tabular}

Abbreviations: C/N, carbon/nitrogen; PCNM, principal coordinates of neighbor matrices.

$P$-values in bold indicate the significance level $<0.05$.

confirmed in our analysis using a single host genus, Abies (Supplementary Figure S4).

The host family has been reported to influence EM fungal composition at the global scale 
(Tedersoo et al., 2012). However, whether EM fungal composition is driven by host identity per se or other confounding environmental factors is unknown because climate and geological history inherently affect host distributions at the global scale. In contrast, we clearly showed that host identity had a minor role in explaining EM fungal composition at the regional scale. First, different host genera coexisting at the same site tended to harbor similar EM fungi (Figure 2b). Second, although we detected significant host effects in the environmental fitting test (Table 4), the hosts alone were insignificant when environmental factors were excluded in the variation partitioning analysis (Figure 3). Finally, mountain-shared species tended to occur in similar forests on different mountains, but not strictly on the same hosts (Supplementary Figure S3). Thus, any host effect at the global scale would be a consequence of climate and geological history, and not derived from phylogenetic constraints between the symbiotic partners.

The lack of large host effects at the regional scale may be related to our studied system that was dominated by generalist EM partners. Our forests were composed of typical EM host trees (e.g., Fagus, Quercus and Abies) that harbored generalist EM fungal groups such as Russulaceae and Thelephoraceae (Smith et al., 2009). In contrast, host effects would be more prominent for specialist symbionts, such as Alnus-Alpova and Pinus-Rhizopogon (Molina et al., 1992; Kennedy and Hill, 2010). Indeed, we detected some host-specific fungal genera such as Suillus and Tylospora, which occurred only on conifer hosts. But their occurrence appeared to be too low to separate the communities among hosts. Moreover, the significance of host effects would depend on spatial scales and host composition within a stand. Our stand-scale analyses detected significant host effects at some sites, especially in gymnosperm-angiosperm mixed forests (Miyamoto, unpublished data; Supplementary Table S3), as in many previous studies (Ishida et al., 2007; Tedersoo et al., 2008; Smith et al., 2009). However, most EM fungi are assumed to be host generalists (Bruns et al., 2002), which is supported by numerous studies (Kennedy et al., 2003; Roy et al., 2008; Trocha et al., 2012; Bahram et al., 2013b). Therefore, although the host may influence the EM fungal community within a narrow range of climatic conditions at stand scales, the effect could be masked by more dominant determinants (e.g., climate) at larger spatial scales. Plant communities are well known to be primarily determined by climate, and to some extent by soil conditions, within a biogeographic region (Kira, 1991; Morin et al., 2007). This is largely because climatic conditions (e.g., temperature and precipitation) and nutrients are the major growth-limiting resources for autotrophic plants. Both this work and previous studies (Bahram et al., 2012) have indicated that temperature and precipitation could restrict EM fungal distributions.
We found a positive correlation between the compositional similarities of EM fungi and trees in the Mantel test, which agreed with previous studies on plant and fungal communities at regional scales (Edwards and Zak, 2010; Peay et al., 2013). However, these correlations do not necessarily represent the direct links between plants and microorganisms, and the empirical evidence of direct links appears to be inconclusive (Waldrop et al., 2006; Bryant et al., 2008; Queloz et al., 2011; van der Putten et al., 2013). In fact, hosts per se had little predictive power with regard to the EM fungal composition in our analysis. Thus, EM fungi and trees may synchronously, but independently, respond to the same environmental factors, particularly climatic conditions. Global climate change is becoming a serious issue in forest ecosystems (Bonan, 2008; Allen et al., 2010). Given the short generation turnover (Wadud et al., 2014), EM fungi may exhibit a higher adaptive capacity to environmental change than trees. Our data provide important insights that host plants and mutualistic fungi may respond to climate change idiosyncratically, potentially altering carbon and nutrient cycles in relation to the plant-fungus associations.

We investigated seven sites using the intensive sampling approach combined with molecular identifications of both EM fungi and hosts. Although there is a trade-off between the intensity of sampling and number of sampling sites in microbial ecological studies (Miyamoto et al., 2014), the number of sites in this study was sufficient to demonstrate the strong climatic effects on EM fungal community structures while excluding the effects of geographical distance and hosts at the regional scale. Extending the intensive sampling approach to other biogeographic regions in future studies would help to clarify the relative importance of biogeographic history and climate on distributions and community structures of EM fungi.

\section{Conflict of Interest}

The authors declare no conflict of interest.

\section{Acknowledgements}

We thank Ai Shimizu and Takuya Yamazaki for field assistance; Dr Kenshiro Oshima, Emi Omori and Yukiko Takayama for assistance in sequencing. This project was funded by the Grants-in-Aid for JSPS Fellows to YM and Grants-in-Aid for Scientific Research to KN.

\section{References}

Allen CD, Macalady AK, Chenchouni H, Bachelet D, McDowell N, Vennetier M et al. (2010). A global overview of drought and heat-induced tree mortality 
reveals emerging climate change risks for forests. Forest Ecol Manage 259: 660-684.

Anderson MJ. (2001). A new method for non-parametric multivariate analysis of variance. Austral Ecol 26: 32-46.

Bahram M, Koljalg U, Courty P-E, Diedhiou AG, Kjoller R, Põlme S et al. (2013a). The distance decay of similarity in communities of ectomycorrhizal fungi in different ecosystems and scales. J Ecol 101: 1335-1344.

Bahram M, Koljalg U, Kohout P, Mirshahvaladi S, Tedersoo L. (2013b). Ectomycorrhizal fungi of exotic pine plantations in relation to native host trees in Iran: evidence of host range expansion by local symbionts to distantly related host taxa. Mycorrhiza 23: 11-19.

Bahram M, Põlme S, Koljalg U, Zarre S, Tedersoo L. (2012). Regional and local patterns of ectomycorrhizal fungal diversity and community structure along an altitudinal gradient in the Hyrcanian forests of northern Iran. New Phytol 193: 465-473.

Bonan GB. (2008). Forests and climate change: forcings, feedbacks, and the climate benefits of forests. Science 320: $1444-1449$.

Borcard D, Gillet F, Legendre P. (2011). Numerical Ecology with $R$, 3rd edn. Springer: New York.

Borcard D, Legendre P, Avois-Jacquet C, Tuomisto H. (2004). Dissecting the spatial structure of ecological data at multiple scales. Ecology 85: 1826-1832.

Bruns TD, Bidartondo MI, Taylor DL. (2002). Host specificity in ectomycorrhizal communities: what do the exceptions tell us? Integr Comp Biol 42: $352-359$

Bryant JA, Lamanna C, Morlon H, Kerkhoff AJ, Enquist BJ, Green JL. (2008). Microbes on mountainsides: contrasting elevational patterns of bacterial and plant diversity. Proc Natl Acad Sci USA 105: 11505-11511.

Carignan V, Villard MA. (2002). Selecting indicator species to monitor ecological integrity: a review. Environ Monit Assess 78: 45-61.

Colwell RK, Chao A, Gotelli NJ, Lin S-Y, Mao CX, Chazdon RL et al. (2012). Models and estimators linking individual-based and sample-based rarefaction, extrapolation and comparison of assemblages. J Plant Ecol 5: 3-21.

Cox F, Barsoum N, Lilleskov EA, Bidartondo MI. (2010). Nitrogen availability is a primary determinant of conifer mycorrhizas across complex environmental gradients. Ecol Lett 13: 1103-1113.

Dickie IA, Koele N, Blum JD, Gleason JD, McGlone MS. (2014). Mycorrhizas in changing ecosystems. Botany 92: 149-160.

Douhan GW, Rizzo DM. (2005). Phylogenetic divergence in a local population of the ectomycorrhizal fungus Cenococcum geophilum. New Phytol 166: $263-271$.

Dray S, Legendre P, Peres-Neto PR. (2006). Spatial modelling: a comprehensive framework for principal coordinate analysis of neighbour matrices (PCNM). Ecol Model 196: 483-493.

Edwards IP, Zak DR. (2010). Phylogenetic similarity and structure of Agaricomycotina communities across a forested landscape. Mol Ecol 19: 1469-1482.

FAO (2012). Global forest land-use change 1990-2005. Lindquist EJ, D’Annunzio R, Gerrand A, MacDicken K, Achard F, Beuchle R et al. FAO Forestry Paper No.169. Food and Agriculture Organization of the United Nations and European Commission Joint Research Centre: Rome.
Ishida TA, Nara K, Hogetsu T. (2007). Host effects on ectomycorrhizal fungal communities: insight from eight host species in mixed conifer-broadleaf forests. New Phytol 174: 430-440.

Jarvis S, Woodward S, Alexander IJ, Taylor AFS. (2013). Regional scale gradients of climate and nitrogen deposition drive variation in ectomycorrhizal fungal communities associated with native Scots pine. Global Change Biol 19: 1688-1696.

Johnson NC, Angelard C, Sanders IR, Kiers ET. (2013). Predicting community and ecosystem outcomes of mycorrhizal responses to global change. Ecol Lett 16: 140-153.

Katoh K, Toh H. (2008). Recent developments in the MAFFT multiple sequence alignment program. Brief Bioinform 9: 286-298.

Kennedy PG, Hill LT. (2010). A molecular and phylogenetic analysis of the structure and specificity of Alnus rubra ectomycorrhizal assemblages. Fungal Ecol 3: 195-204.

Kennedy PG, Izzo AD, Bruns TD. (2003). There is high potential for the formation of common mycorrhizal networks between understorey and canopy trees in a mixed evergreen forest. J Ecol 91: 1071-1080.

Kira T. (1991). Forest ecosystems of east and southeast Asia in a global perspective. Ecol Res 6: 185-200.

Koide RT, Fernandez C, Malcolm G. (2014). Determining place and process: functional traits of ectomycorrhizal fungi that affect both community structure and ecosystem function. New Phytol 201: 433-439.

Leibold MA, Mikkelson GM. (2002). Coherence, species turnover, and boundary clumping: elements of meta-community structure. Oikos 97: 237-250.

Lilleskov EA, Bruns TD, Horton TR, Taylor DL, Grogan P. (2004). Detection of forest stand-level spatial structure in ectomycorrhizal fungal communities. FEMS Microbiol Ecol 49: 319-332.

Lilleskov EA, Parrent JL. (2007). Can we develop general predictive models of mycorrhizal fungal community-environment relationships? New Phytol 174: 250-256.

Martiny JBH, Bohannan BJM, Brown JH, Colwell RK, Fuhrman JA, Green JL et al. (2006). Microbial biogeography: putting microorganisms on the map. Nat Rev Microbiol 4: 102-112.

Miyamoto Y, Nakano T, Hattori M, Nara K. (2014). The mid-domain effect in ectomycorrhizal fungi: range overlap along an elevation gradient on Mount Fuji, Japan. ISME J 8: 1739-1746.

Molina R, Massicotte H, Trappe JM. (1992). Specificity phenomena in mycorrhizal symbioses: communityecological consequences and practical implications. In: Allen MF (ed), Mycorrhizal Functioning: An Integrative Plant-Fungal Process. Chapman and Hall: New York, pp 357-423.

Morin X, Augspurger C, Chuine I. (2007). Process-based modeling of species' distributions: what limits temperate tree species' range boundaries? Ecology 88: 2280-2291.

Murata M, Kinoshita A, Nara K. (2013). Revisiting the host effect on ectomycorrhizal fungal communities: implications from host-fungal associations in relict Pseudotsuga japonica forests. Mycorrhiza 23: 641-653.

Nakagawa S, Santos ESA. (2012). Methodological issues and advances in biological meta-analysis. Evol Ecol 26: $1253-1274$. 
Parrent JL, Morris WF, Vilgalys R. (2006). CO2-enrichment and nutrient availability alter ectomycorrhizal fungal communities. Ecology 87: 2278-2287.

Peay KG, Baraloto C, Fine PVA. (2013). Strong coupling of plant and fungal community structure across western Amazonian rainforests. ISME J 7: 1852-1861.

Peay KG, Bruns TD, Kennedy PG, Bergemann SE, Garbelotto M. (2007). A strong species-area relationship for eukaryotic soil microbes: island size matters for ectomycorrhizal fungi. Ecol Lett 10: 470-480.

Pickles BJ, Genney DR, Anderson IC, Alexander IJ. (2012). Spatial analysis of ectomycorrhizal fungi reveals that root tip communities are structured by competitive interactions. Mol Ecol 21: 5110-5123.

Presley SJ, Higgins CL, Willig MR. (2010). A comprehensive framework for the evaluation of metacommunity structure. Oikos 119: 908-917.

Põlme S, Bahram M, Yamanaka T, Nara K, Cheng Dai Y, Grebenc T et al. (2013). Biogeography of ectomycorrhizal fungi associated with alders (Alnus spp.) in relation to biotic and abiotic variables at the global scale. New Phytol 198: 1239-1249.

Queloz V, Sieber TN, Holdenrieder O, McDonald BA, Grunig CR. (2011). No biogeographical pattern for a root-associated fungal species complex. Global Ecol Biogeogr 20: 160-169.

$\mathrm{R}$ Development Core Team (2013). R: A Language and Environment for Statistical Computing. R Foundation for Statistical Computing: Vienna, Austria, Available from http://www.R-project.org.

Read DJ, Perez-Moreno J. (2003). Mycorrhizas and nutrient cycling in ecosystems-a journey towards relevance? New Phytol 157: 475-492.

Richard F, Millot S, Gardes M, Selosse MA. (2005). Diversity and specificity of ectomycorrhizal fungi retrieved from an old-growth Mediterranean forest dominated by Quercus ilex. New Phytol 166: 1011-1023.

Roy M, Dubois M-P, Proffit M, Vincenot L, Desmarais E, Selosse M-A. (2008). Evidence from population genetics that the ectomycorrhizal basidiomycete Laccaria amethystina is an actual multihost symbiont. Mol Ecol 17: 2825-2838.

Roy M, Rochet J, Manzi S, Jargeat P, Gryta H, Moreau P-A et al. (2013). What determines Alnus-associated ectomycorrhizal community diversity and specificity? A comparison of host and habitat effects at a regional scale. New Phytol 198: 1228-1238.

Smith ME, Douhan GW, Fremier AK, Rizzo DM. (2009). Are true multihost fungi the exception or the rule? Dominant ectomycorrhizal fungi on Pinus sabiniana differ from those on co-occurring Quercus species. New Phytol 182: 295-299.

Smith SE, Read DJ. (2008). Mycorrhizal Symbiosis, 3rd edn. Elservier: New York.

Taberlet P, Gielly L, Pautou G, Bouvet J. (1991). Universal primers for amplification of 3 noncoding regions of chloroplast DNA. Plant Mol Biol 17: 1105-1109.

Tamura K, Stecher G, Peterson D, Filipski A, Kumar S. (2013). MEGA6: Molecular Evolutionary Genetics Analysis version 6.0. Mol Biol Evol 30: 2725-2729.
Taylor AFS. (2002). Fungal diversity in ectomycorrhizal communities: sampling effort and species detection. Plant Soil 244: 19-28.

Taylor AFS, Alexander I. (2005). The ectomycorrhizal symbiosis: life in the real world. Mycologist 19: 102-112.

Tedersoo L, Bahram M, Dickie IA. (2014). Does host plant richness explain diversity of ectomycorrhizal fungi? Re-evaluation of Gao et al. (2013) data sets reveals sampling effects. Mol Ecol 23: 992-995.

Tedersoo L, Bahram M, Toots M, Diedhiou AG, Henkel TW, Kjoller R et al. (2012). Towards global patterns in the diversity and community structure of ectomycorrhizal fungi. Mol Ecol 21: 4160-4170.

Tedersoo L, Jairus T, Horton BM, Abarenkov K, Suvi T, Saar I et al. (2008). Strong host preference of ectomycorrhizal fungi in a Tasmanian wet sclerophyll forest as revealed by DNA barcoding and taxon-specific primers. New Phytol 180: 479-490.

Tedersoo L, May TW, Smith ME. (2010). Ectomycorrhizal lifestyle in fungi: global diversity, distribution, and evolution of phylogenetic lineages. Mycorrhiza 20: 217-263.

Tedersoo L, Mett M, Ishida TA, Bahram M. (2013). Phylogenetic relationships among host plants explain differences in fungal species richness and community composition in ectomycorrhizal symbiosis. New Phytol 199: 822-831.

The Japan Meteorological Agency (2014). Mesh Average 2010. Japan Meteorological Business Support Center: Tokyo, Japan.

Thébault E. (2013). Identifying compartments in presence-absence matrices and bipartite networks: insights into modularity measures. J Biogeogr 40: 759-768.

Toljander JF, Eberhardt U, Toljander YK, Paul LR, Taylor AF. (2006). Species composition of an ectomycorrhizal fungal community along a local nutrient gradient in a boreal forest. New Phytol 170: 873-883.

Trocha LK, Kalucka I, Stasinska M, Nowak W, Dabert M, Leski T et al. (2012). Ectomycorrhizal fungal communities of native and non-native Pinus and Quercus species in a common garden of 35-year-old trees. Mycorrhiza 22: 121-134.

Twieg BD, Durall DM, Simard SW. (2007). Ectomycorrhizal fungal succession in mixed temperate forests. New Phytol 176: 437-447.

van der Putten WH, Bardgett RD, Bever JD, Bezemer TM, Casper BB, Fukami T et al. (2013). Plant-soil feedbacks: the past, the present and future challenges. J Ecol 101: 265-276.

Verhoeven KJF, Simonsen KL, McIntyre LM. (2005). Implementing false discovery rate control: increasing your power. Oikos 108: 643-647.

Wadud MA, Nara K, Lian C, Ishida TA, Hogetsu T. (2014). Genet dynamics and ecological functions of the pioneer ectomycorrhizal fungi Laccaria amethystina and Laccaria laccata in a volcanic desert on Mount Fuji. Mycorrhiza 24: 551-563.

Waldrop MP, Zak DR, Blackwood CB, Curtis CD, Tilman D. (2006). Resource availability controls fungal diversity across a plant diversity gradient. Ecol Lett 9: 1127-1135.

Supplementary Information accompanies this paper on The ISME Journal website (http://www.nature.com/ismej) 